\title{
Habitat use in the female Alpine long-eared bat (Plecotus macrobullaris): does breeding make the difference?
}

\author{
Damiano G. Preatoni ${ }^{1,2}$, Martina Spada $^{1}$, Lucas A. Wauters ${ }^{1}$, Guido Tosi ${ }^{1}$, and Adriano Martinoli ${ }^{1}$ \\ ${ }^{1}$ Dipartimento di Scienze Teoriche e Applicate, Università degli Studi dell'Insubria, Via J. H. Dunant 3, 21100 Varese, Italy \\ ${ }^{2}$ Corresponding author: E-mail: prea@uninsubria.it
}

\begin{abstract}
Recent discoveries of several new cryptic bat species in Europe, as well as the growing concerns on bat conservation, have resulted in increased efforts to study roost site selection, habitat use and spacing/foraging behaviour. For many of these cryptic species, management is problematic due to the lack of information. We present data on space and habitat use of 14 radio-tagged Plecotus macrobullaris females from a nursery in the central part of the species' distribution. They used home ranges larger than $10 \mathrm{~km}^{2}$, and the behavioural pattern was typically a first foraging bout soon after emergence from the nursery, followed by fast non-foraging flight towards selected habitat types. Habitat selection, as evaluated by K-select analysis, is non-random with preference for ecotones at woodland borders and rural areas, whereas woods are avoided. Body condition differentially affects habitat use for breeding and non-breeding females: breeding females in good condition showed a strong preference for ecotones. Among non-breeding females, the preference for ecotones varied with body condition. Being the sibling species of $P$. auritus, which is considered a woodland bat, the selection pattern observed for $P$. macrobullaris raises some questions about the possible niche partition in cases of sympatry.
\end{abstract}

Key words: Plecotus macrobullaris, habitat selection, home range size, radio-tracking, Italy

\section{INTRODUCTION}

Recent discoveries of several new, cryptic bat species in Europe, and the growing importance of bat conservation have resulted in an increased research effort to study roost site selection, habitat use and spacing/foraging behaviour of (rare) bat species (Arlettaz, 1999; Mayer and von Helversen, 2001; Mickleburgh et al., 2002; Di Salvo et al., 2009; Whitaker and Karataş, 2009). In fact, before their distinction, cryptic species were biogeographically and ecologically confounded, calling for a careful re-evaluation of their distribution and ecological requirements (Arlettaz, 1999; Sattler et al., 2007; Ashrafi et al., 2010). Habitat requirements may differ even among closely related species: according to the principle of competitive exclusion, species in the same community tend to differentiate their resource exploitation strategies to achieve stable coexistence. Hence, sibling species may co-exist because of niche partitioning (Arlettaz, 1999; Patterson et al., 2003; Russo et al., 2005). Therefore, determining their space and habitat use is essential to understand levels of interspecific competition between them when they occur in sympatry, and to gather a better understanding of factors influencing structure and diversity of bat communities.

Recent identification of new sibling species of long-eared bats (genus Plecotus) have increased the number of European species from two (brown longeared bat, $P$. auritus and grey long-eared bat, $P$. austriacus) to six (P. macrobullaris - Kiefer and Veith, 2001; Spitzenberger, 2003; P. kolombatovici Mayer and von Helversen, 2001; Spitzenberger et al., 2002; P. sardus, endemic to Sardinia Mucedda et al., 2002; P. teneriffae, endemic to the Canary Islands - Ibáñez and Fernández, 1985; Juste et al., 2004). The Alpine long-eared bat, $P$. macrobullaris, is a sibling species of $P$. auritus (Kiefer and Veith, 2001). It can be reliably identified by mitochondrial DNA sequencing (Kiefer and Veith, 2001; Kiefer et al., 2002; Trizio et al., 2003); recently, a discriminant function based on body measurements has been proposed which correctly classified $97.5 \%$ of specimens as belonging to the Plecotus sibling species present in the Alps (Ashrafi et al., 2010). The known distribution range of $P$. macrobullaris extends from the Pyrenees to Greece and Crete, including the Alps from France to Slovenia (Kiefer and von Helversen, 2004). 
In northern Italy it has been recorded in prealpine and alpine landscapes, throughout the Italian Alps (Kiefer and Veith, 2001; Spitzenberger et al., 2002; Chirichella et al., 2003; Trizio et al., 2003), confirming the preference for mountainous habitats (Kiefer et al., 2002). In most of this range it is sympatric with $P$. auritus.

Currently, there are no data on space and habitat use of $P$. macrobullaris. Thus, basic ecological information essential for the development of species management are lacking. Moreover, nothing is known about possible niche partitioning between sympatric populations of $P$. macrobullaris and P. auritus.

Here we present the first data on the space and habitat use of radio-tagged P. macrobullaris. Since the most important management units (MU) in bat populations in the temperate zone are the nurseries, we radio-tagged 14 females from a single nursery in the central part of the species' distribution.

\section{Materials AND Methods}

\section{Study Area}

The study was conducted in the Campo dei Fiori Regional Park, Lombardy, in northern Italy $\left(45^{\circ} 53^{\prime} \mathrm{N}, 8^{\circ} 47^{\prime} \mathrm{E}\right)$, a 5,400ha densely forested pre-alpine area made of two peaks, Mounts Campo dei Fiori (1,227 m a.s.1.) and Martica (1,032 $\mathrm{m}$ a.s.l.) and an intermediate valley ( $470 \mathrm{~m}$ a.s.l.). Mean annual temperature (between $9^{\circ}$ and $12^{\circ} \mathrm{C}$ ) and precipitation (between 1,004 and $2,000 \mathrm{~mm}$ ) vary with elevation. Mean temperature of the warmest month is $22^{\circ} \mathrm{C}$, mean winter temperature ranges between $0^{\circ}$ and $2^{\circ} \mathrm{C}$ (data recorded by the Centro Geofisico Prealpino weather station at Mt. Campo dei Fiori). The study area (covering $285 \mathrm{~km}^{2}$ ) was determined by calculating a minimum convex polygon (MCP) that included all locations of the radio-tagged bats (Russo et al., 2002) and, subsequently, adding an external buffer zone whose width was determined by the average value of distances between the roost and fixes recorded for tracked subjects calculated using a spider diagram (Hooge and Eichenlaub, 1997). The area is largely covered with woodlands $(65 \%)$, dominated by sweet chestnut (Castanea sati$v a$ ), durmast oak (Quercus petraea) and birch (Betula sp.) below $800 \mathrm{~m}$ a.s.l., while beech (Fagus sylvatica) dominates at higher elevations.

\section{Trapping and Handling Bats}

During bat monitoring activities in 1996, a $P$. macrobullaris maternity roost was discovered in the roof of a church (Brinzio) which was surrounded by extensive forested areas. The species' identity was confirmed by DNA analysis (Trizio et al., 2005). Bats were captured while leaving the roost in the evening in June-July 2002 and 2003 with a nylon twisted-thread mistnet $(3 \times 3 \mathrm{~m}, 19 \mathrm{~mm}$ wide square mesh) near the roost entrance. Bats were weighed to the nearest $0.1 \mathrm{~g}$ with an electronic scale (Maul Tronic, Germany) and forearm length was measured with precision callipers $( \pm 0.1 \mathrm{~mm})$. Sex was assessed by inspecting external genitalia (Racey and Swift, 1981) and wings were trans-illuminated to distinguish juveniles from adults, the former showing cartilage epiphyseal plates in finger bones (metacarpal-phalangeal joint of the fourth finger - Kunz, 1988). A body condition index was calculated as the ratio between body mass and forearm length (Russo et al., 2001). Fourteen females (three subadults, two non-breeding adults, nine breeding adults - Table 1) were fitted with $0.47 \mathrm{~g}$ Holohil LB-2 transmitters (Holohil Systems Ltd., Ontario, Canada) attached between the scapulae with Skinbond ${ }^{\circledR}$ surgical glue after partly trimming the fur. Transmitter lifetime was 7 to 20 days and a single bat was monitored for $2-16$ nights $(\bar{x} \pm \mathrm{SD}=7 \pm 5$ nights - Table 1).

Bats were tracked on foot and by car using JDS Executive 2000 radio-receivers (Wildlife Materials, Inc., Carbondale, USA) fitted with three-element hand-held directional Yagi antennas. The study area was scanned for radio-signals mostly from fixed vantage points to maximise radio-signal detection. Location of all fixes, included those from fixed vantage points were mapped using a GPS (GPS II Garmin, Garmin Ltd., Olathe, Kansas, USA) and stored in UTM coordinates (WGS84 datum, EPSG code 32632). The first night after capture, we tracked all tagged bats to make sure tags did not affect their natural behaviour.

On the following nights, a focal animal was selected for tracking starting immediately after it left the roost (between 20.00 and 21.00 solar time) until its return (around 3.30 to 4.30 solar time). When a focal subject was lost for over 30 minutes, we switched to another one. The position of the focal animal was determined every 15 minutes using triangulation (White and Garrott, 1990; Entwistle et al., 1996) by two or more operators who simultaneously detected the bearings of the signal using a 1 degree precision compass (Suunto KB-14, Vantaa, Finland). On average, the distance between the operators and tracked animals was variable from 0.1 to $1 \mathrm{~km}$. Moreover, when bats were foraging in a restricted area we used homing-in to determine the exact locations in order to observe them during foraging activities (see also Entwistle et al., 1996). At each location, we recorded the position of the operators, the estimated location in UTM coordinates and the bat activity (categorised as foraging, commuting, roosting, undetermined). Activity was established based on the variation in signal intensity over a 1-minute period: when animals were resting (motionless) intensity readings on the receiver amperometer remained stable, while the signal of active, flying bats was characterised by a marked variation in intensity.

\section{Home Range Analysis}

All radio-tracking data were converted to the Italian coordinate reference system (Gauss-Boaga, West zone, Rome 1940 datum, EPSG 3003) in a GIS database (ESRI Arcview 3.2, ESRI Inc., 1999), and Locate II 3.11 software (Nams, 2000) was used to triangulate the bearings and obtain the corresponding fixes. Home range size was estimated with the $95 \%$ fixed density kernel estimator (95\% KDE, Worton 1989) using the R software (version 2.9.0 - R Development Core Team, 2010) package adehabitat (Calenge, 2006), with the adjusted smoothing factor $h_{\text {adj }}$ calculated according to Wauters et al. (2007). Since our aim was to estimate home range size and habitat use of active bats, locations occurring in the main roost during day-time were not used in home range calculation. 


\section{Habitat Selection}

K-select analysis (Calenge et al., 2005) was used to study habitat selection, using the tools provided by the $\mathrm{R}$ package adehabitat (Calenge, 2006). K-select analysis is a recently introduced technique, specifically designed for radio-tracking data, that relies on the classical ecological niche paradigm: an ecological space is defined by several maps, each one representing a single habitat variable (such as elevation, percentage of woodlands, etc.), i.e. a single dimension in the ecological space. Thus, average habitat conditions can be calculated, as well as average conditions for each animal. The difference between the vector of average available habitat conditions and the vector of average conditions for each animal is defined as the marginality vector: it is proportional to the importance of habitat selection, and its direction indicates selection or avoidance. Using principal component analysis on the marginality vectors of each animal and the habitat variables, the K-select analysis yields a linear combination of habitat variables for which the average marginality is greatest, that is a synthesis of the environmental variables taken into account which contributes the most to habitat selection. Marginality and specialisation vectors significance were calculated using a 10,000-fold randomisation test. All the raster data used as environmental variables in $\mathrm{K}$-select analysis were pre-processed using GRASS GIS version 6.4.0 (GRASS Development Team, 2010).

For K-select analysis purposes, we determined the availability of the following environmental variables (in \% cover inside the study area): agricultural land, meadows, shrubland, wetlands, woods and sparsely inhabited rural areas (small villages). These data were extracted from an existing land cover digital vector map (Carta della Vegetazione Reale della Provincia di Varese - Tosi and Zilio, 2002) at an equivalent scale of $1: 10,000$, that was rasterised at a $50-\mathrm{m}$ spatial resolution and reclassified according to the above land cover categories. Habitats used were quantified by counting $50 \mathrm{~m}$ grid cells for each habitat type contained in the 95\% Utilisation Distribution (UD) isopleth (Calenge et al., 2005). Furthermore, as an index of ecotone density, the perimeter/area ratio per each $50 \mathrm{~m}$ cell was calculated based on boundary extent between polygons classified as 'woods' and 'meadows'. We employed a 20 -m digital elevation model (Regione Lombardia, 2003) to determine elevation.

\section{RESULTS}

Between 13 and 254 locations were collected per individual $(n=14, \bar{x} \pm \mathrm{SD}=95 \pm 75)$. For two animals home range calculation was not possible: one animal had too few locations (10), whereas for a second animal the $h_{\text {adj }}$ estimation procedure did not converge.

Home range size differed considerably between individuals (range 84-3,388 ha - Table 1). It was not affected by the number of locations used for estimation (Pearson correlation $r=0.04, n=12$, $P>>0.05)$ and did not differ between breeding and non-breeding females $(t=-0.70, P>>0.05)$. On average, $18 \%$ of all fixes concerned bats in the main roost at night-time and $14 \%$ in temporary roosts, all

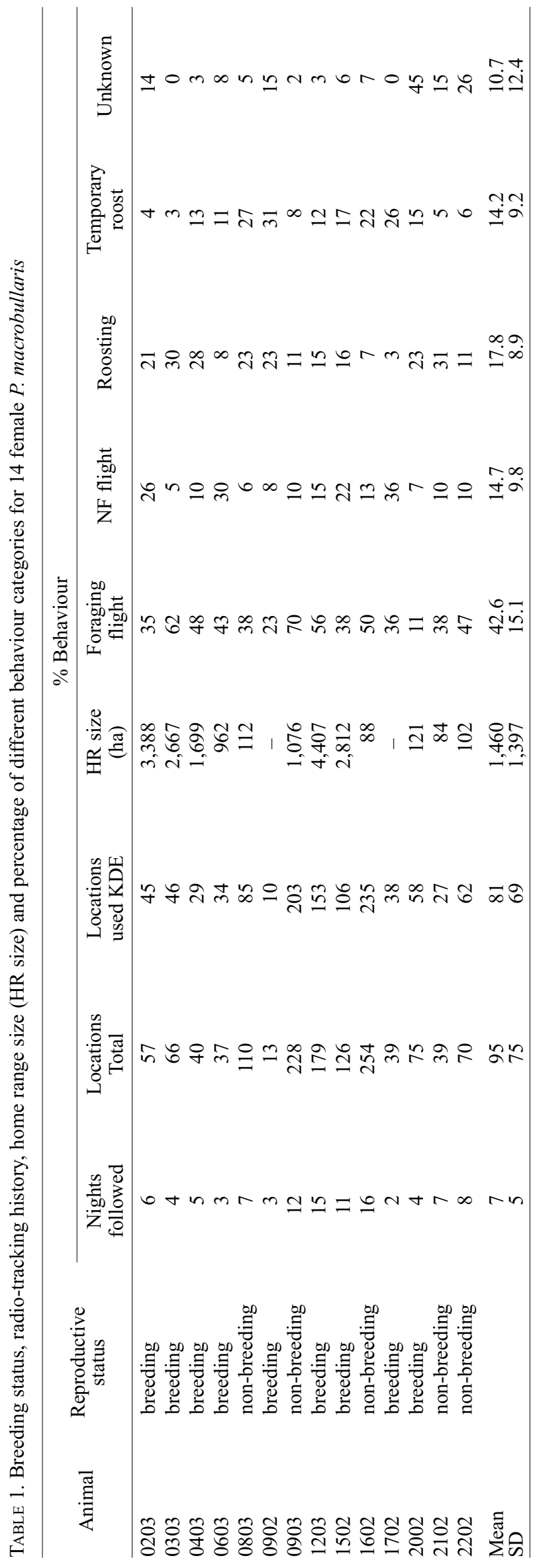


in building lofts and garrets. The dominant activity was foraging ( $43 \%$ of all fixes). Commuting flights, mainly directly oriented, almost straight-line movements from roost to foraging areas, were less frequent $(15 \%$ - Table 1$)$.

Mean distance travelled (from roost) was 1,068 \pm $1,563 \mathrm{~m}$. For individual bats, the shortest average distance from the roost was $260 \mathrm{~m}$, the longest $2,265 \mathrm{~m}$. Overall, more than $50 \%$ of fixes were within $500 \mathrm{~m}$ from the roost, and about $75 \%$ within $1 \mathrm{~km}$ (Fig. 1). However, some bats regularly commuted to foraging sites more than $2-3 \mathrm{~km}$ from the roost, with a maximum distance of $7.1 \mathrm{~km}$ (Fig. 1).

Habitat use was non-random, as revealed by the significance reached by the first eigenvalue in the K-select test $\left(\lambda_{1}=2.55, P<0.001\right)$; the first canonical axis accounts for $94.3 \%$ of the total variance. This canonical axis (Fig. 2, variables plot) represents an ecotone gradient (PCA normed score $=0.36$ ), also influenced in opposite ways by the percentage of rural area (score $=0.67)$ and woodlands (score $=-0.61$ ). An open area (i.e. meadows) cover gradient could explain the second K-select canonical axis (meadows normed score $=0.84$ ).

Based on randomisation tests on the marginality vectors, habitat use was significantly non-random for 10 out of 12 bats (Table 2). Shrubland, wetlands and agricultural areas were used opportunistically by all but one bat that significantly avoided the latter. All bats except one (bat 0303) preferred

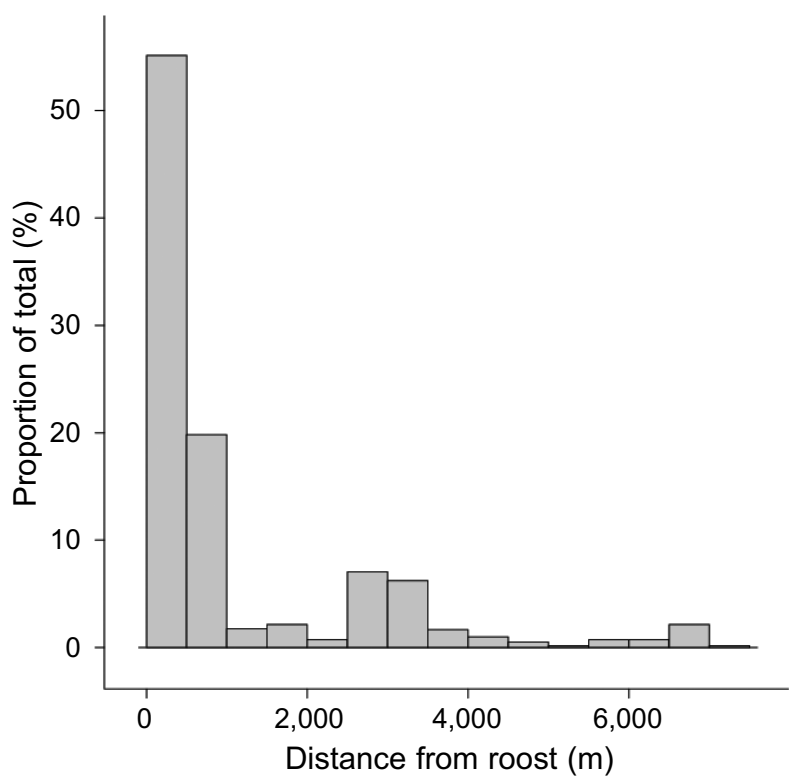

FIG. 1. Frequency distribution of location distances $(500 \mathrm{~m}$ classes) from the nursery roost for $P$. macrobullaris females

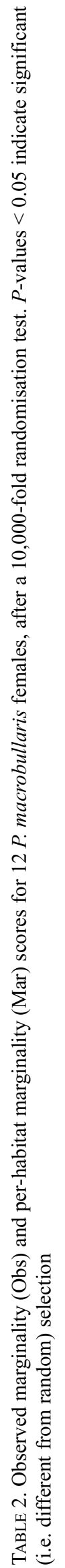


ecotones and rural areas (villages) and avoided woods (Fig. 2). Bat 0303 alone used higher than random elevations and did not avoid woods. The marginality vectors for each bat (Fig. 2, marginality vectors) show a general tendency towards high use of ecotones and open areas (meadows). There are no evident differences between breeding and nonbreeding females.

Since both breeding status and body condition might affect habitat use, we explored the effect of body condition for breeding and non-breeding females separately. In breeding females the marginality score was positively correlated with body condition $(r=0.82, n=7, P<0.05)$. In contrast, body condition of non-breeding bats was negatively correlated with the marginality score $(r=-0.95, n=5$, $P<0.05)$, thus an opposite trend. This was mainly due to breeding females in good condition selecting more strongly for ecotones (Fig. 3), while nonbreeding females in good condition selected less for ecotones than those in poorer condition.

\section{DisCUSSION}

\section{Data Reliability}

Although our sample size was limited (albeit comparable with other studies on space use and foraging activities of bats - see, e.g., Lučan and
Radil, 2010; Monadjem et al., 2010; Ralisata et al., 2010; Zahn et al., 2010), this is the first study of space and habitat use in P. macrobullaris. Since our study area was large and included several different habitat types, our data are important to gain knowledge on the ecological niche of this recently discovered species and compare it with that of its sympatric sibling species.

We tried to reduce sources of error that could affect the accuracy of our data. First, we admit that there might be an error on locations estimated using triangulation, which could cause incorrect identification of the habitat for some of these locations. However, the landscape was coarse-grained and most patches of a given habitat were large. Moreover, triangulation was mainly used when bats moved away from the nursery roost, thus for nonforaging flights. In any case, as Plecotus is a lowspeed, low-power flyer (Neuweiler, 2000) we can reasonably assume a fair accuracy in triangulation. When we were able to relocate the focal animal, we used homing-in when signal indicated resting and determined the exact position (and thus habitat type) of the temporary roost. Also, homing-in or triangulation from a short distance of the focal bat $(<100 \mathrm{~m})$ was used when it was hunting in a restricted area. This was indeed the case for the majority of locations of foraging bats. This approach allowed us to check the accuracy of use of ecotones,

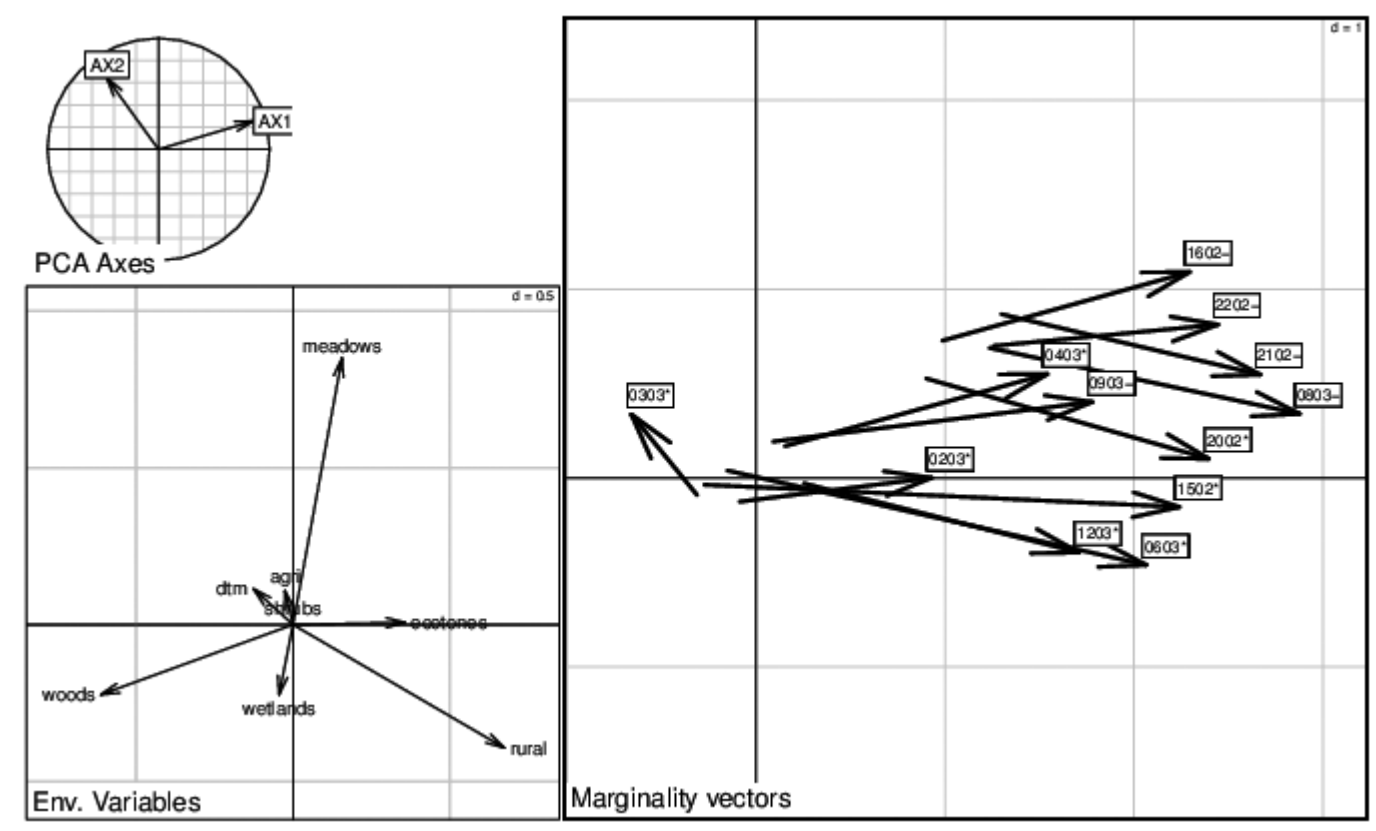

FIG. 2. Results of K-select analysis for habitat selection of 12 P. macrobullaris females. Axis: correlation between K-select and the first two PCA axes. Env. Variables: environmental variables loadings on the first two canonical axes. Marginality vectors: representation of the uncentered marginality vectors for each animal: arrow starts indicate available habitat, arrow ends indicate used habitat. The asterisk besides animal ID indicates a breeding animal, the dash a non-breeding one 


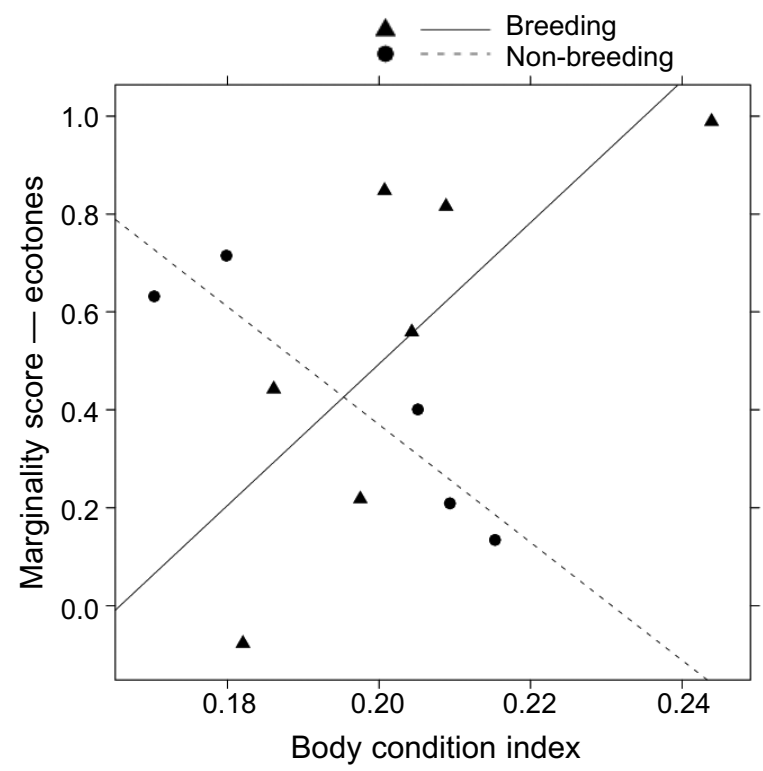

FIG. 3. Relationship between body condition index of female P. macrobullaris and the marginality score for ecotones as calculated by K-select analysis. Correlation between body condition index and ecotone marginality score: breeding females, $r=0.77, P<0.05$; non-breeding females, $r=-0.93$, $P<0.05$

essential for the interpretation of our data. Second, several previous radio-tracking studies on bats, including $P$. auritus, suggested that radio-tagged animals might change their behaviour the first night after tagging (Hughes and Rayner, 1991; Adam et al., 1994). Therefore, data from the first night were not used for space and habitat use analysis.

\section{Space Use and Habitat Selection}

In rural landscapes, as our study area, bat activity is sometimes centered at woodland fragments (Gehrt and Chelsvig, 2003) and vegetation density is often the best predictor among microhabitat characteristics to determine the overall bat habitat use (Smith and Gerth, 2010). However bats may exhibit interspecific variation in response to the percentage of woodland presence and forest characteristics due to variation in wing morphology, acoustic structure, and foraging strategy (Norberg and Rayner, 1987). Female $P$. macrobullaris used large home ranges and most animals had ranges larger than $10 \mathrm{~km}^{2}$. Such large home ranges and marked individual variation in range size was also recorded for Barbastella barbastellus, a species with similar feeding techniques (125 to 2,551 ha - Hillen et al., 2009, 2010). Home range size was affected by the behavioural pattern observed in most radio-tagged bats. After emergence from the nursery, most bats foraged in the vicinity of the roost for a short period after which they typically made fast non-foraging flight towards selected habitat types. In fact, habitat use was non-random and all radio-tagged bats, except one, strongly selected ecotones and rural areas (villages) for foraging, and avoided woods. This is in strong contrast to the marked preference for (deciduous or mixed) woods and the lack of selection for ecotones by $P$. auritus in the UK (Entwistle et al., 1996).

The space use pattern found in this study for P. macrobullaris was very different from that of another gleaning bat, Myotis bechsteinii. This species used small home ranges (16.1-34.7 ha) containing very small core foraging areas $(50 \%$ kernel, 2.1 ha, range: 1.7-2.6 ha - Dietz and Pir, 2009). In the majority of cases, female Bechstein's bats had two foraging areas, one of them close to the day-roost $(<500 \mathrm{~m})$ and one further away but within $1 \mathrm{~km}$. All radio-tracked females used woodland for foraging and selected deciduous forests, with old oak trees often covering more than $40 \%$ of the stands, and a closed (> 75\%) canopy (Dietz and Pir, 2009). Breeding females of Myotis daubentoni also used small, individual foraging areas during pregnancy and lactation (Dietz and Kalko, 2007).

Why did the P. macrobullaris use such large home ranges? This pattern could be explained by the Resource Dispersion Hypothesis (RDH) which predicts that if there is spatial or temporal heterogeneity in resource availability, then home range size will primarily depend on the spatial dispersion of resource patches, whereas group size (in our case size of the breeding colony) will be limited by prey richness in the available resource patches (Carr and MacDonald, 1986; Johnson et al., 2002). Hence, variation in home range size of bats will not only be a function of insect prey availability in patches but also of spatial dispersion of the patches of preferred habitat types. Each bat is likely to grant a sufficient number of food-rich patches in its home range to reach a critical probability that enough food is available over time (Carr and MacDonald, 1986).

\section{Breeding Condition and Habitat Selection}

Among bats, habitat quality, and in particular food supply, affect the distribution of nursery colonies, of the sexes (e.g., Russo, 2002) and, in some cases, can cause differences in space use patterns between breeding and non-breeding females (Speakman et al., 1991). Having higher energyrequirements than non-breeding females, pregnant 
and lactating females drastically increase food intake and can consume up to more than two thirds of their individual body mass in arthropods per night (Anthony and Kunz, 1977; Encarnação and Dietz, 2006). Hence, differential energy-constraints might result in different patterns of habitat selection in these two groups (e.g., Dietz and Pir, 2009). For example, the short, broad wings and low wing loading of $M$. bechsteinii guarantee high manoeuvrability and enable the bats to hover (Norberg and Rayner, 1987), allowing them to exploit different prey items within a short range: consequently breeding females tend to become territorial to secure sufficient food intake in small, non-overlapping core (feeding) areas (Kerth et al., 2001; Dietz and Kalko, 2007; Dietz and Pir, 2009). However, when feeding sites are fragmented and widely distributed in the landscape, territoriality is unlikely, and costs of commuting will increase especially in species with short, broad wings and low wing loading as longeared bats (Norberg and Rayner, 1987). In this case, selection for dispersed, high-quality habitats, could be stronger in animals of better condition. This was the case for the breeding female alpine long-eared bats in this study, as suggested by the positive correlation of body condition (BCI) with the ecotone marginality score. Hence, breeding females in good condition selected more strongly for ecotones than those in poorer condition. In contrast, this trend did not occur among non-breeding females which even showed an opposite (negative) relationship between body condition and ecotone marginality score. The different habitat selection patterns between breeding and non-breeding females did not result in a significant difference in home range size, although four out of five non-breeding females used relatively small home ranges of about 100 ha.

A possible explanation for the negative relationship between body condition and ecotone selection among non-breeding females is that non-reproducing bats with high $\mathrm{BCI}$ do not need to increase fat reserves and consequently select less for foraging areas with more abundant food resources, as reported in birds (Ekman and Lilliendahl, 1993). In contrast, non-reproducing females with a low BCI need to select food-rich habitat types to increase body mass, as predicted by the good feeding patch hypothesis (Cuadrado, 1997). Moreover, bats of the genus Plecotus can detect and prey on non-flying prey (Norberg and Rayner, 1987; Anderson and Racey, 1993), which may help to explain that non-breeding females with high BCI can obtain sufficient food without strong selection for ecotone foraging areas.

\section{The Use of Rural Areas}

Agricultural landscapes are mosaics of human land use and remnant natural systems. Rural landscapes, where tree rows or remnant forest fragments are present in a low-altered environment, may be particularly important for bats (Swystun et al., 2001; Menzel et al., 2002; Russo et al., 2002). Bat species that appear better adapted to rural landscapes with urban development are those that do not require tree cavities for roosting but use roofs or crevices in anthropic sites and/or are better suited to fly in open areas. In contrast, species that are less common in more urbanised landscapes and occur more frequently in more forested landscapes have higher wing tip shape index and lower wing loading, adaptations to flight in a more complex, cluttered environment of woods with mixed canopy structure (Norberg and Rayner, 1987; Duchamp and Swihart, 2008). The wing morphology of bats of the genus Plecotus is that of gleaning bats adapted to hunt in complex, forested habitats, and the sibling species of P. macrobullaris, P. auritus, typically hunts in areas with a high woodland cover, roosting in natural tree cavities, caves and often in wood-lined buildings close to woodland (Entwistle et al., 1996; MitchellJones et al., 1999). In fact, in Central Europe and the Alps, $P$. auritus and $P$. austriacus are believed to co-exist because of niche partitioning: $P$. auritus selecting mainly forested areas, while $P$. austriacus is more associated with lowland and more open agricultural landscapes, hunting in urbanised areas and roosting in various types of buildings (Piechocki, 1966; Bauerová, 1982, Fuhrmann and Seitz, 1992; Entwistle et al., 1996).

Female $P$. macrobullaris in this study showed habitat use patterns more similar to $P$. austriacus than to P. auritus. All day and night roosts of our radio-tagged females were in buildings and several bats were observed foraging at orchards, around a golf course and even under street lights, explaining the positive selection for the rural habitat. Moreover, comparison of the echolocation signals of $P$. macrobullaris with those of $P$. auritus and $P$. austriacus reveals a greater similarity with the latter species, although P. macrobullaris is genetically more closely related to $P$. auritus (Juste et al., 2004; Dietrich et al., 2006). Data from faeces analysis support the hypothesis that $P$. austriacus may also hunt for aerial insects (Bauerová, 1982; Beck, 1995) whereas P. auritus predominantly gleans its prey from surfaces (e.g., Swift and Racey, 1983; Rydell, 1989; Meineke, 1991; Beck, 1995). 
So far, there are no data available on the prey spectrum of $P$. macrobullaris. However, morphological data, such as the length of the upper canine, which are about the same the length as in $P$. austriacus (Mucedda et al., 2002) suggest that P. macrobullaris might also be able to handle larger prey than P. auritus.

Finally, although $P$. auritus is considered a woodland bat, studies in heterogeneous landscapes showed that its space and habitat use are flexible with bats using gardens, park and conifer forest ecotones for hunting (Swift and Racey, 1983; Fuhrmann and Seitz, 1992). Therefore, we conclude that further studies should concentrate on space use and habitat selection of sympatric alpine and brown longeared bats to explore whether the two siblings species partition the spatial or habitat niche dimension.

\section{ACKNOWLEDGEMENTS}

We are grateful to the Campo dei Fiori Natural Park for collaboration and Roberta Chirichella, Simone Mastrota, Sabrina Mattiroli, Mosè Nodari, Elena Riva who helped with the fieldwork. We are also indebted to Danilo Russo who revised an early draft of the manuscript and to Jens Rydell and an anonymous referee for their precious suggestions.

\section{Literature Cited}

ADAM, M. D., M. J. LACKI, and T. G. BARNES. 1994. Foraging area and habitat use of the Virginia big-eared bat in Kentucky. Journal of Wildlife Management, 58: 462-469.

ANDERSON, M. E., and P. A. RACEY. 1993. Discrimination between fluttering and nonfluttering moths by brown long-eared bats, Plecotus auritus. Animal Behaviour, 46: 1151-1155.

Anthony, E. L. P., and T. H. Kunz. 1977. Feeding strategies of the little brown bat, Myotis lucifugus, in southern New Hampshire. Ecology, 58: 775-786.

ARLETTAZ, R. 1999. Habitat selection as a major resource partitioning mechanism between the two sympatric sibling bat species Myotis myotis and Myotis blythii. Journal of Animal Ecology, 68: 460-471.

Ashrafi, S., F. Bontadina, A. Kiefer, I. Pavlinic, and R. ArLETTAZ. 2010. Multiple morphological characters needed for field identification of cryptic long-eared bat species around the Swiss Alps. Journal of Zoology (London), 281: 241-248.

BAuerová, Z. 1982. Contribution to the trophic ecology of the grey long-eared bat, Plecotus austriacus. Folia Zoologica, 31: 113-122.

BECK, A. 1995. Fecal analysis of European bat species. Myotis, 32/33: 109-119.

CALENGE, C. 2006. The package adehabitat for the R software: a tool for the analysis of space and habitat use by animals. Ecological Modelling, 197: 516-519.

Calenge, C., A. Dufour, and D. Maillard. 2005. K-select analysis: a new method to analyse habitat selection in radiotracking studies. Ecological Modelling, 186: 143-153.
CARR, G. M., and D. W. Macdonald. 1986. The sociality of solitary foragers: a model based on resource dispersion. Animal Behaviour, 34: 1540-1549.

Chirichella, R., S. Mattiroli, M. Nodari, D. G. Preatoni, L. A. Wauters, G. Tosi, and A. Martinoli. 2003. The Adamello-Brenta Natural Park bat community (Mammalia, Chiroptera): distribution and population status. Hystrix, the Italian Journal of Mammalogy, 14: 29-45.

CUADRADO, M. 1997. Why are migrant robins (Erithacus rubecula) territorial in winter?: the importance of the antipredatory behaviour. Ethology Ecology and Evolution, 9: 77-88.

Dietrich, S., D. P. Szameitat, A. Kiefer, H.-U. Schnitzler, and A. DENZINGER. 2006. Echolocation signals of the plecotine bat, Plecotus macrobullaris Kuzyakin, 1965. Acta Chiropterologica, 8: 465-475.

DietZ, M., and E. K. V. KaLKo. 2007. Reproduction affects flight activity in female and male Daubenton's bats, Myotis daubentoni. Canadian Journal of Zoology, 85: 653-664.

DieTZ, M., and J. B. PIR. 2009. Distribution and habitat selection of Myotis bechsteinii in Luxembourg: implications for forest management and conservation. Folia Zoologica, 58: 327-340.

Di Salvo, I., D. Russo, and M. SARÀ. 2009. Habitat preferences of bats in a rural area of Sicily determined by acoustic surveys. Hystrix, the Italian Journal of Mammalogy, 20: $137-146$.

Duchamp, J. E., and R. K. Swihart. 2008. Shifts in bat community structure related to evolved traits and features of human-altered landscapes. Landscape Ecology, 23: 849-860.

Ekman, J., and K. LiLLIENDAHL. 1993. Using priority to food access: fattening strategy in dominance structured willow tit Parus montanus flocks. Behavioural Ecology, 4: 232-238.

EnCARnaÇão, J. A., and M. Dietz. 2006. Estimation of food intake and ingested energy in Daubenton's bats (Myotis daubentonii) during pregnancy and spermatogenisis. European Journal of Wildlife Research, 52: 221-227.

Entwistle, A. C., P. A. Racey, and J. R. Speakman. 1996. Habitat exploitation by a gleaning bat, Plecotus auritus. Philosophical Transactions of the Royal Society of London, 351B: 921-931.

Fuhrmann, M., and A. Seitz. 1992. Nocturnal activity of the brown long-eared bat (Plecotus auritus L., 1758): data from radio-tracking in the Lenneberg forest near Mainz (Germany). Pp. 538-548, in Wildlife telemetry. Remote monitoring and tracking of animals (I. G. PRIEDE and S. M. SwIFT, eds.). Ellis Horwood, Chichester, 708 pp.

GehrT, S. D., and J. E. Chelsvig. 2003. Bat activity in an urban landscape: patterns at the landscape and microhabitat scale. Ecological Applications, 13: 939-950.

Grass Development Team. 2010. Geographic resources analysis support system (GRASS) software, version 6.4.0. Open Source Geospatial Foundation. http://grass.osgeo.org. Accessed 25 November 2010.

Hillen, J., A. Kiefer, and M. Veith. 2009. Foraging site fidelity shapes the spatial organisation of a population of female western barbastelle bats. Biological Conservation, 142: 817-823.

Hillen, J., A. Kiefer, and M. Veith. 2010. Interannual fidelity to roosting habitat and flight paths by female western barbastelle bats. Acta Chiropterologica, 12: 187-195.

Hooge, P. N., and B. Eichenlaub. 1997. Animal movement extension to ArcView. ver. 1.1. Alaska Science Center - 
Biological Science Office, U.S. Geological Survey, Anchorage, USA.

Hughes, P. M., and J. M. V. RAYNER. 1991. Addition of artificial loads to long-eared bats, Plecotus auritus, handicapping flight performance. Journal of Experimental Biology, 161: 285-298.

IBÁÑEZ, C., and R. FERnÁndEZ. 1985. Systematic status of the long-eared bat Plecotus teneriffae Barret-Hamilton, 1907 (Chiroptera; Vespertilionidae). Säugetierkundliche Mitteilungen, 32: 143-149.

Johnson, D. D., R. Kays, P. G. Blackwelld, and D. W. MaCDONALD. 2002. Does the resource dispersion hypothesis explain group living? Trends in Ecology and Evolution, 17: $563-570$.

Juste, J., C. Ibáñez, D. Muñoz, D. Trujillo, P. Benda, A. KaRATAS, and M. RUEDI. 2004. Mitochondrial phylogeography of the long-eared bats (Plecotus) in the Mediterranean Palaearctic and Atlantic Islands. Molecular Phylogenetics and Evolution, 31: 1114-1126.

Kerth, G., M. Wagner, and B. König. 2001. Roosting together, foraging apart: information transfer about food is unlikely to explain sociality in female Bechstein's bats ( $M y$ otis bechsteinii). Behavioral Ecology and Sociobiology, 50: 283-291.

Kiefer, A., and M. Veith. 2001. A new species of long-eared bat from Europe (Chiroptera: Vespertilionidae). Myotis, 39: $5-16$.

Kiefer, A., and O. von Helversen. 2004. Plecotus alpinus. Pp. 1051-1058, in Handbuch der Säugetiere Europas, Band 4/2, (F. KrAPP, ed.). Aula-Verlag, Wiebelsheim, 1181 pp.

Kiefer, A., F. Mayer, J. Kosuch, O. von Helversen, and M. Veith. 2002. Conflicting molecular phylogenies of European long-eared bats (Plecotus) can be explained by cryptic diversity. Molecular Phylogenetics and Evolution, 25: 557-566.

KunZ, T. H. (ed.). 1988. Ecological and behavioral methods for the study of bats. Smithsonian Institution Press, Washington D.C., 533 pp.

LUČAN, R. K., and J. RADIL. 2010. Variability of foraging and roosting activities in adult females of Daubenton's bat (Myotis daubentonii) in different seasons. Biologia, 65/66: 1072-1080.

Mayer, F., and O. von Helversen. 2001. Cryptic diversity in European bats. Proceedings of the Royal Society of London, 268B: 1825-1832.

Menzel, M. A., T. C. Carter, J. M. Menzel, W. M. Ford, and B. R. CHAPMAN. 2002. Effects of group selection silviculture in bottomland hardwoods on the spatial activity patterns of bats. Forest Ecology and Management, 162: 209-218.

MeINEKE, T. 1991. Auswertung von Fraßresten der beiden Langohrarten Plecotus auritus (Linnaeus, 1758) und Plecotus austriacus (Fischer, 1829). Naturschutz und Landschaftspflege in Niedersachsen, 26: 37-45.

Mickleburgh, S. P., A. M. Hutson, and P. A. Racey. 2002. A review of the global conservation status of bats. Oryx, 36: $18-34$.

Mitchell-Jones, A. J., G. Amori, W. Bogdanowicz, B. KryŠtufeK, P. ReiJnders, J. M. Ziman, B. KryštufeK, F. SPItZenberger, M. Stubbe, J. Thissen, V. Vohralík, and J. ZIMA. 1999. The atlas of European mammals. T. \& A. D. Poyser, London, $483 \mathrm{pp}$.

Monadjem, A., T. RaAbe, B. Dickerson, N. Silvy, and R. McCleERY. 2010. Roost use by two sympatric species of
Scotophilus in a natural environment. South African Journal of Wildlife Research, 40: 73-76.

Mucedda, M., A. Kiefer, E. Pidinchedda, and M. Veith. 2002. A new species of long-eared bat (Chiroptera, Vespertilionidae) from Sardinia (Italy). Acta Chiropterologica, 4: 121-135.

NAMS, V. O. 2000. Locate III - radiotelemetry triangulation program. Pacer Computing, Tatamagouche, NS, Canada. http:// www.locateiii.com. Accessed 19 January 2010.

NeuweILER, G. 2000. The biology of bats. Oxford University Press, New York, 310 pp.

Norberg, U. M., and J. M. V. RaYNER. 1987. Ecological morphology and flight in bats (Mammalia: Chiroptera): wing adaptations, flight performance, foraging strategy and echolocation. Philosophical Transactions of the Royal Society of London, 316B: 335-427.

Patterson, B. D., M. R. Willing, and R. D. Stevens. 2003. Trophic strategies, niche partitioning and patterns of ecological organization. Pp. 536-579, in Bat ecology (T. H. KunZ and M. B. Fenton, eds.). University of Chicago Press, Chicago, $779 \mathrm{pp}$.

PIECHOCKI, R. 1966. Über die Nachweise der Langohr-Fledermäuse Plecotus auritus (Linnaeus, 1758) und Plecotus austriacus (Fischer, 1829) im mitteldeutschen Raum. Hercynia, 3: 407-415.

R Development Core Team. 2010. R: a language and environment for statistical computing. R Foundation for Statistical Computing, Vienna, Austria.

RACEY, P. A., and S. M. SwIFT. 1981. Variations in gestation length in a colony of pipistrelle bats (Pipistrellus pipistrellus) from year to year. Journal of Reproduction and Fertility, 61: 123-129.

Ralisata, M., F. R. ANDRIAMBoAVonjy, D. RaKotondRaVony, O. R. RaVoahangimalala, F. H. RANDRIANANDRIANINA, and P. A. RACEY. 2010. Monastic Myzopoda: the foraging and roosting ecology of a sexually segregated Malagasy endemic bat. Journal of Zoology (London), 282: 130-139.

REgione Lombardia. 2003. DTM20 - Modello Digitale del Terreno. Regione Lombardia, Infrastruttura per l'Informazione Territoriale. http://www.cartografia.regione.lombardia.it. Accessed 25 November 2010.

Russo, D. 2002. Elevation affects the distribution of the two sexes in Daubenton's bats Myotis daubentonii (Chiroptera: Vespertilionidae) from Italy. Mammalia, 66: 543-551.

Russo, D., G. Jones, and M. MucEDDA. 2001. Influence of age, sex and body size on echolocation calls of Mediterranean (Rhinolophus euryale) and Mehely's (Rhinolophus mehelyi) horseshoe bats (Chiroptera: Rhinolophidae). Mammalia, 65: 429-436.

Russo, D., G. Jones, and A. MigLiozzi. 2002. Habitat selection by the Mediterranean horseshoe bat, Rhinolophus euryale (Chiroptera: Rhinolophidae) in a rural area of southern Italy and implications for conservation. Biological Conservation, 107: 71-81.

Russo, D., D. Almenar, J. Aihartza, U. Goiti, E. SalsamenDI, and I. GARIN. 2005. Habitat selection in sympatric Rhinolophus mehelyi and $R$. euryale (Mammalia: Chiroptera). Journal of Zoology (London), 266: 327-332.

RYDELL, J. 1989. Food habits of northern (Eptesicus nilssoni) and brown long-eared (Plecotus auritus) bats in Sweden. Holarctic Ecology, 12: 26-20.

Sattler, T., F. Bontadina, A. H. Hirzel, and R. Arlettaz. 2007. Ecological niche modelling of two cryptic bat species 
calls for a reassessment of their conservation status. Journal of Applied Ecology, 44: 1188-1199.

SMith, D. A., and S. D. GeHRT. 2010. Bat response to woodland restoration within urban forest fragments. Restoration Ecology, 18: 914-923.

Speakman, J. R., P. A. Racey, C. M. C. Catto, P. I. Webb, S. M. SwifT, and A. M. BuRnetT. 1991. Minimum summer populations and densities of bats in N.E. Scotland, near the northern borders of their distribution. Journal of Zoology (London), 225: 32-345.

Spitzenberger, F., E. Haring, and N. TVRTKovic. 2002. Plecotus microdontus (Mammalia, Vespertilionidae), a new bat species from Austria. Natura Croatica, 11: 1-18.

Spitzenberger, F., P. Strelkov, and E. Haring. 2003. Morphology and mitochondrial DNA sequences show that Plecotus alpinus Kiefer \& Veith, 2002 and Plecotus microdontus Spitzenberger, 2002 are synonyms of Plecotus macrobullaris Kuzjakin, 1965. Natura Croatica, 12: 39-53.

SwIFT, S. M., and P. A. RACEY. 1983 Resource partitioning in two species of vespertilionid bats (Chiroptera) occupying the same roost. Journal of Zoology (London), 200: 249-259.

Swystun, M. B., J. M. Psyllakis, and R. M. Brigham. 2001. The influence of residual tree patch isolation on habitat use by bats in central British Columbia. Acta Chiropterologica, 3: 197-201.

Tosi, G., and A. ZiLIo. 2002. Conoscenza delle Risorse Ambientali della Provincia di Varese — Progetto SIT —
Fauna. Provincia di Varese, Settore Politiche per l'Agricoltura e Gestione Faunistica, 297 pp.

Trizio, I., E. Patriarca, P. Debernardi, D. Preatoni, G. Tosi, and A. Martinoli. 2003. The Alpine long-eared bat (Plecotus alpinus, Kiefer and Veith, 2001) is present also in Piedmont region: first record revealed by DNA analysis. Hystrix, the Italian Journal of Mammalogy, 14: 113-115.

Trizio, I., D. Preatoni, R. Chirichella, S. Mattiroli, M. Nodari, S. Crema, G. Tosi, and A. Martinoli. 2005. First record of the Alpine long-eared bat (Plecotus macrobullaris Kuzjakin, 1965) in Lombardy revealed by DNA analysis. Natura Bresciana, Annali del Museo Civico di Scienze Naturali, 34: 171-175.

Wauters, L. A., D. G. Preatoni, A. Molinari, and G. Tosi. 2007. Radio-tracking squirrels: performance of home range density and linkage estimators with small range and sample size. Ecological Modelling, 202: 333-344.

Whitaker, J. O., JR., and A. Karataş. 2009. Food and feeding habits of some bats from Turkey. Acta Chiropterologica, 11: 393-403.

White, G. C., and R. A. Garrott. 1990. Analysis of wildlife radio-tracking data. Academic Press, London, $383 \mathrm{pp}$.

WorTON, B. J. 1989. Kernel methods for estimating the utilization distribution in home-range studies. Ecology, 70: 164-168.

Zahn, A., S. Bauer, E. Kriner, and J. Holzhaider. 2010. Foraging habitats of Myotis emarginatus in Central Europe. European Journal of Wildlife Research, 56: 395-400.

Received 19 January 2011, accepted 05 August 2011 